\title{
Understanding Consumers' Intention of Adopting Smartphone-facilitated Service Apps in Mobile-enhanced Retailing Business
}

\author{
Yu-Teng Jacky Jang1, Shuchih Ernest Chang2* ${ }^{2}$, Anne Yenching Liu ${ }^{3}$, Kevin Lai ${ }^{4}$ \\ 1 Department of Business Administration, Tunghai University. No.1727, Sec.4, Taiwan Boulevard, Xitun \\ District, Taichung 407, Taiwan. \\ 2 Institute of Technology Management, National Chung Hsing University. No. 145, Xingda Road, South \\ District, Taichung 402, Taiwan. \\ 3 Department of International Trade, Chihlee University of Technology. No. 313, Sec. 1, Wunhua Road., \\ Banciao District, New Taipei City 22050, Taiwan. \\ 4 Mills College, Oakland, California 94613, USA. \\ * Corresponding author. Tel.:+886-4-22840547\#607; email: eschang@dragon.nchu.edu.tw \\ Manuscript submitted March 31, 2017; accepted May 31, 2017.
}

doi: 10.17706/ijeeee.2018.8.1.26-33

\begin{abstract}
This study aims to explore how the consumers' intention of adopting SFS Apps can be affected in the current highly competitive and multi-channel business context. A research framework with five hypotheses was proposed to study important relationships between the constructs of social and ranking influence, economic consideration, application quality, functionality of mobile device, and intention of adopting SFS Apps for small retailing business. An empirical test was conducted by using PLS, a second-generation multivariate analysis tool, to analyze survey data collected from 145 SFS App users. Findings revealed that social and ranking influence would significantly and positively affect not only consumers' economic consideration but also application quality. In addition, consumers' intention of adopting SFS Apps was found to be significantly and positively affected by both application quality and functionality of mobile device. However, there was no evidence showing that functionality of mobile device was significantly associated with consumers' economic consideration. The validated research model and corresponding findings can be referenced by small mobile-enhanced retailing business executives and decision makers for making favorable tactics to take advantage of the revolutionary benefits offered by SFS Apps.
\end{abstract}

Key words: Consumer behavioral intention, mobile commerce, mobile-enhanced retailing, partial least squares (PLS), smartphone application (App).

\section{Introduction}

"Smartphone" has dramatically changed people's daily lives and business landscape. Due to advanced technologies in smartphone computing, storage, and transmission capabilities, people nowadays can take advantage of a global connectivity of a wide range of services through their smartphones in a multimodal pervasive environment. Such advancement not only provides users with attractive convenience and added values but also drives the electronic commerce (e-commerce) evolvement and development for small business. To meet consumers' various needs, many traditional retailing stores (such as McDonald's and Starbucks) have started to utilize various channels of the Internet and attempted to develop their own 
smartphone-facilitated service applications (SFS Apps) to extend and expand their business boundary by incorporating mobile commerce (m-commerce) activities into their current e-commerce models [1], [2].

Such a "mobile-enhanced retailing" approach to providing expanded accessibility, timely updated content, and novel experience to consumers is expected to increase the value for customers in various market segments [3]. Through incorporating SFS Apps into the current business model, business owners not only can distribute timely information to and collect feedback from consumers interactively but also create a new channel to promote retailing products/services, increase sales volume, and serve their customers' various needs. Although computer-based e-commerce systems and architectures have been proposed and discussed in prior studies [4], there still exist limited prior research devoting efforts to addressing SFS Apps related issues and exploring consumers' intention of adopting SFS Apps in small retailing business context. The validated research model and corresponding findings can be referenced by small mobile-enhanced retailing business executives and smartphone-facilitated service designers for making favorable tactics to take advantage of the revolutionary benefits offered by SFS Apps. The rest of the paper is organized as follows. Section 2 provides the theoretical background and Section 3 describes the hypotheses, framework, and data collection of this research. The empirical study results together with detailed data analysis are shown in Section 4. Section 5 highlights important findings and presents discussions to help recognize and explain the research findings.

\section{Research Background}

\subsection{Smartphone-Facilitated Services and Applications}

Advances in technology, enterprises nowadays are allowed to offers a variety of services through smartphones to meet the diverse needs of consumers, these smartphone-facilitated services usually rely on a dedicated application (App) to carry our specific tasks and deliver services requested by users and consumers. By March 29 of 2017, there are around 2,800,000 available Apps in Google Play Store and around 2,200,000 Apps in Apple's App Store [5]. Take Apple's App Store as an example, the statistics show that gaming Apps are the most popular app category and generate more than 1 million U.S. dollars per day, while business apps are the second-most popular category, with a share of 9.88 percent of all active apps [6]. Emerging with the advent of smartphone technology and the popularity of App usage, small retailing business now has the chance to open up a mobile channel to serve their consumers in a more efficient way. By adopting SFS Apps, consumers are expected to receive various benefits such as cost saving, prompt coupon delivery, personalized and location-based services, and enhanced transaction quality, etc.

\section{Research Model, Hypotheses, and Research Method}

Under the multi-channel retailing (MCR) environment, a traditional retailer can use the "mobile-enhanced retailing" approach to increase the value for current and new customers in various market segments [7]-[10]. In addition to launching a website and offering services to meet consumers' online information search and purchasing needs, retailers now have a new approach (i.e., using SFS Apps) to conduct advertising and marketing campaigns at low cost. Specifically, this study aims to explore how consumers' intention of adopting SFS Apps can be affected in the current highly competitive and multi-channel business context. The operational definitions for each construct and the hypotheses between each construct are addressed as follows.

\subsection{Social and Ranking Influence}

Social influence has been identified as a key element in affecting people's beliefs, feelings and behaviors [11]. Friends, family members, and colleagues are usually regarded as one of the main sources of social 
influence. The ranking reflects the evaluation feedback derived from a majority of users/consumers after their adoption or trial for particular products or services. It's very likely that people would tend to or tend not to adopt something based on other people's feedbacks and behaviors (e.g., comments) [12], [13].

\subsection{Economic Consideration}

Economic consideration is an important factor not only for companies to operate successful business, but helps consumers to make relatively suitable decisions for adoption specific products/services in the process of evaluation [14]. It's likely that consumers' economic consideration would be affected by other people's feedbacks, and behaviors as well as the ranking scores on the platform. Consequently, our first hypothesis was postulated as follows.

H1: Social and ranking influence has a significant impact on consumers' economic consideration in adopting SFS Apps.

\subsection{Application Quality}

Application quality might be associated with many elements perceived by users, such as response time, usefulness, searching efficiency, information completeness/richness/consistency, compatibility, etc. [15], [16], but what a consumer typically cares about is a more integrated perception which consists of accuracy, usefulness, and satisfaction. It's likely that application quality would be affected by social and ranking influence because consumers' comments and feedbacks tend to complete when more people adopt/comment/share it, thus resulting in continuous improvements in application quality. In addition, social influence was found to have significant impact on perceived usefulness in technology acceptance model proposed by Venkatesh et al., (2003) [17]. Accordingly, Hypothesis H2 was posited.

H2: Social and ranking influence has a significant impact on the application quality of SFS Apps.

\subsection{Functionality of Mobile Device}

In prior m-commerce study conducted by Wu and Wang (2005) [18], it was argued that the cost of adopting m-commerce would significantly and negatively influence the intention of adoption, and the perceived usefulness was found to have significantly positive impact on the intention of adoption. But there was relatively limited research emphasizing on exploring the relationship between the perceived cost (e.g. the cost of smartphone acquisition, monthly subscription fee, data fee, etc.) and the functionality of mobile devices. To explore a plausible relationship between economic consideration and functionality of mobile devices, Hypothesis $\mathrm{H} 3$ was postulated.

H3: Economic consideration has a significant impact on the functionality of mobile device.

\subsection{Intention of Adoption}

Consumers might need the adopted SFS Apps with high quality, such as providing a stable connection, user-centric designs, on-demand services, accurate and useful information, etc. Therefore, it was expected in our research model that application quality would have significant impact on intention to adopt SFS Apps. Hypothesis $\mathrm{H} 4$ was hence derived.

H4: Application quality significantly influences consumers' intention to adopt SFS Apps.

Users tend to regard the essential abilities and capability (such as computing ability, storage capacity, supportive connection standards, type of sensors, etc.) of their smartphones as valuable resources; therefore, some of the users would choose not to download and run the Apps with large size or heavy computing loading, and some of them would simply delete/uninstall the Apps after they have shortly tried them. Based on aforementioned statements, hypothesis $\mathrm{H} 5$ was postulated.

H5: Functionality of mobile device has a significant impact on consumers' intention to adopt SFS Apps. 


\subsection{Research Framework, Questionnaire, and Sampling Procedures}

According to the relationships between the important constructs described above, a research framework for exploring how consumers' intention of adopting smartphone-facilitated service applications (SFS Apps) in the context of MCR was constructed and shown in Fig. 1. Based on the research framework and the postulated hypotheses, a questionnaire was developed as the survey instrument to validate the measurement model and test the structural model.

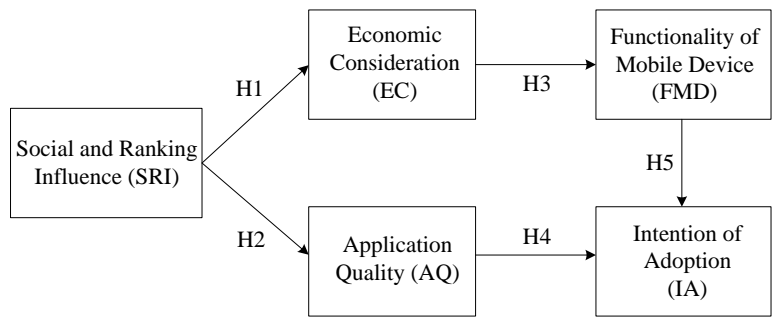

Fig. 1. Research framework.

Empirical data was collected through a questionnaire-based online survey, by posting invitations on e-commerce related news groups and websites to recruit respondents with the experience of using smartphone-facilitated service Apps. The questionnaire was developed from an integrated process referencing the results from the literature review and the research framework. Our approach was modified from the similar method used by Lee and Kim (2008) [19]. Except for the demographic related questions, the questionnaire items were measured using a five-point Likert scale, ranging from "strongly disagree (1)" to "strongly agree (5)". To ensure that the items could be understood and measured validly, a pretest was conducted in a small group. Based on the comments received from the pretest and the findings derived from pretest results, modifications were made to the items before they were used in the formal survey.

Partial least squares (PLS), is suggested as a powerful path modeling tool which requires minimum restrictions on measure scales and sample size, i.e., it can be used to model latent constructs under conditions of nonnormality and small to medium sample sizes [20], [21]. The second-generation multivariate analysis tool, SmartPLS 2.0.M3 [22], was used in this study to analyze collected samples and test the measurement model. It is important to assess the accuracy of the measurement model (i.e., the outer model which connects the manifest variables to the latent variables) in terms of the individual item reliability, construct reliability, convergent and discriminant validity of the variables in the model. Following the suggestions from Tenenhaus et al. (2005) [21], a check for unidimensionality of each block in the proposed model was conducted before applying PLS analysis on the collected data and the proposed structure model.

\section{Empirical Analysis and Results}

After a total of 169 respondents were gathered, invalid and incomplete survey results were identified and discarded. Overall, 145 usable copies of the questionnaire were collected and used for analysis. Among 145 usable respondents, 81 (55.9\%) were male and 64 (44.1\%) were female. Accounting for 98.9\%, 142 respondents' ages mainly fell in the range between 16 and 45 years old, matching the main group of smartphone users in Taiwan. Our demographic analysis results also show that 137 (94.5\%) of the respondents have experience of using smartphone for more than half a year. As for the experience in using the Internet, 145 respondents $(100 \%)$ have been surfing the Internet for more than two years, and 121 respondents (83.4\%) claimed that they had experience with online shopping for more than ten times. In terms of educational level, 45 (31\%) of them were at the postgraduate level, and 100 (69\%) were college 
students or had bachelor degrees.

\subsection{Statistics and Unidimensionality Check}

There are three tools available to check the unidimensionality of a block: principal component analysis of the block, Cronbach's alpha $(\alpha)$, and Dillon-Goldstein's rho $(\rho)$ [21]. A block is considered as unidimensional when its Cronbach's alpha value and Dillon-Goldstein's rho $(\rho)$ are larger than 0.7 [21]. As shown in Table 1, the statistics for this check satisfied the aforementioned standards. Therefore, it was concluded that the unidimensionality of all blocks is supported by the test results from all three tools.

Table 1. The Statistics for Checking the Unidimensionality of All Blocks

\begin{tabular}{lllll}
\hline $\begin{array}{l}\text { Latent } \\
\text { variable }\end{array}$ & $\begin{array}{l}\text { First } \\
\text { eigenvalue eigenvalue }\end{array}$ & $\begin{array}{l}\text { Second } \\
\boldsymbol{\alpha}\end{array}$ & $\begin{array}{l}\text { Cronbach's } \\
\text { Goldstein's } \boldsymbol{\rho}\end{array}$ \\
\hline SRI & 2.022 & .606 & .755 & .859 \\
EC & 2.395 & .802 & .775 & .852 \\
AQ & 2.266 & .400 & .837 & .902 \\
FMD & 2.065 & .609 & .761 & .868 \\
IA & 2.295 & .465 & .845 & .907 \\
\hline
\end{tabular}

\subsection{Test of the Measurement Model (Outer Model): Convergent Validity and Discriminant validity Checks}

In this study, all outer loadings were higher than the threshold of 0.7 suggested by prior research [23]. The average variance extracted (AVE) measures can be used to assess the convergent validity of the reflective constructs. All AVE scores in this study ranged from 0.592 to 0.765 , passing the threshold value of 0.5 suggested by [24]. Based on our results from the outer model estimation (weight, loadings, and AVE), the discriminant validity of the constructs used in our study was acceptable, since the square root of AVE on each construct was greater than the correlations of the construct with other constructs.

The matrix of loadings and cross-loading for all indicators our study shows that all reflective items have high loadings on their expected constructs and every item loads higher on its theoretical construct than on other constructs, which provides additional evidence of convergent validity and discriminant validity [25], [26].

\subsection{PLS Path Modeling Results: Structural Model (Inner Model)}

As the inner model results presented in Table 2, our empirical results show that the hypotheses H1, H2, $\mathrm{H} 4$, and $\mathrm{H} 5$ postulated in this study were supported by the empirical results, though the other hypothesis (H3) was not supported.

Table 2. Structural Model Results

\begin{tabular}{lllll}
\hline \multicolumn{1}{c}{ Ho $_{\mathbf{0}}$} & Hypothesis & $\begin{array}{l}\text { Path } \\
\text { coefficient }\end{array}$ & $\boldsymbol{P}$-value & $\begin{array}{l}\text { Hypothesis test } \\
\text { result }\end{array}$ \\
\hline $\mathrm{SRI} \rightarrow \mathrm{EC}$ & $\mathrm{H} 1$ & $0.275^{* *}$ & 0.0041 & supported \\
$\mathrm{SRI} \rightarrow \mathrm{AQ}$ & $\mathrm{H} 2$ & $0.255^{*}$ & 0.0224 & supported \\
$\mathrm{EC} \rightarrow \mathrm{FMD}$ & $\mathrm{H} 3$ & -0.049 & 0.7119 & not supported \\
$\mathrm{AQ} \rightarrow \mathrm{IA}$ & $\mathrm{H} 4$ & $0.319^{* * *}$ & 0.0004 & supported \\
$\mathrm{FMD} \rightarrow \mathrm{IA}$ & $\mathrm{H} 5$ & $0.373^{* *}$ & 0.0074 & supported \\
\hline Notes: $(1)^{*} p^{*}<0.05,{ }^{* *} p<0.01,{ }^{* * *} p<0.001$ & &
\end{tabular}

\section{Discussion and Conclusion}

Through incorporating SFS Apps into the current business model, not only can business owners 
distribute timely information to and collect feedback from consumers interactively but open up a new channel to promote retailing products/services, increase sales volume, and serve their customers' various needs. Motivated by the need to have a better understanding of how consumers' intention of adopting SFS Apps can be affected in the current highly competitive and multi-channel business context, this study proposed a research framework, collected empirical data from 145 participants, and used PLS to analyze the data and validate the framework. Our empirical study results revealed several findings. Firstly, the results suggest that social and ranking influence is an important factor affecting not only consumers' economic consideration but also application quality. A consumer's economic consideration would be affected by the ranking scores as well as his or her friends, classmates, or colleagues. Quality of App would be improved based on consumers' feedbacks, comments, and ranking scores. Secondly, consumers' intention of adopting SFS Apps was found to be significantly and positively affected by both application quality and functionality of mobile device. That implies that both hardware (i.e., functionality of mobile device) and software (i.e., application quality) have positive and significant effect on the intention of adoption. These important findings suggest that social and ranking influence can be considered as the basis of initiating a mutually benefited relationship with their customers. Retailers are suggested to pay more attention to building, operating, and maintaining the possible channels for creating positive social and ranking influence. It would be a promising decision to establish a Facebook fan page for the launched SFS App since Facebook fan pages have been identified as a simple, efficient, and effective tool in maintaining social networks and creating social influence [12], [27]-[30]. In addition, it is suggested that retailers should take consumers' complaints seriously. These complaints may show up and reflect in SFS App ranking scores. Taking consumers' feedbacks seriously and quickly resolving the issues would help to improve the quality of App, which in turn would influence consumers' intention to adopt retailer's SFS Apps. There are thousands of models of smartphones, and millions of Apps on Google Play and Apple's App Store. Designing a SFS App suitable for various smartphone models becomes a vital challenge. Aforementioned implications together with the validated research model can be referenced by small retailing business managers who are conducting mobile-enhanced retailing strategy and using the SFS Apps as the electronic marketing tool to assist sales and increase profit.

\section{References}

[1] McDonald's Corp. (2015). Mobile App. McDonald's Corp. Retrieved from the website: http://www.mcdonalds.com/us/en/mobile_app.html/

[2] Starbucks Corp. (2015). Mobile App. Starbucks Corp. Retrieved from the website: http://www.starbucks.com/coffeehouse/mobile-apps/

[3] Wei, T. T., Marthandan, G., Chong, A. Y.-L., Ooi, K.-B., \& Arumugam, S. (2009). What drives Malaysian m-commerce adoption? An empirical analysis. Industrial Management \& Data Systems, 109(3), 370-388.

[4] Lian, J.-W., \& Lin, T.-M. (2008). Effects of consumer characteristics on their acceptance of online shopping: comparisons among different product types. Computers in Human Behavior, 24(1), 48-65.

[5] Statista.com. (2017). Number of apps available in leading app stores as of March 2017. Statista.com. Retrieved from the website: https://www.statista.com/statistics/276623/number-of-apps-available-in-leading-app-stores/.

[6] Statista.com. (2017). Most popular Apple App Store categories in March 2017, by share of available apps. Statista.com. Retrieved from the website: https://www.statista.com/statistics/270291/popular-categories-in-the-app-store/.

[7] Li, M. Dong, Z.Y., \& Chen, X. (2012). Factors influencing consumption experience of mobile commerce. Internet Research, 22(2), 120-141. 
[8] Wallace, D. W., Giese, J. L., \& Johnson, J. L. (2015). Customer retailer loyalty in the context of multiple channel strategies. Journal of Retailing, 80(4), 249-263.

[9] Müller-Lankenau, C., Wehmeyer, K., \& Klein, S. (2005). Multi-channel strategies: Capturing and exploring diversity in the European retail grocery industry. International Journal of Electronic Commerce, 10(2), 85-122.

[10] Grewal, D., Iyer, G. R., \& Levy, M. (2004). Internet retailing: enablers, limiters and market consequences. Journal of Business Research, 57(7), 703-713.

[11] Mason, W. A., Conrey, F. D., \& Smith, E. R. (2007). Situating social influence processes: Dynamic, multidirectional flows of influence within social networks. Personality and Social Psychology Review, 11(3), 279-300.

[12] Zhou, T. (2011), Understanding online community user participation: A social influence perspective. Internet Research, 21(1), 67-81.

[13] Mei, M., Chow, L. H., Chen, J. A., Yeow, P., \& Wong, W. (2012). Conceptual paper: Factors affecting the demand of smartphone among young adult. International Journal on Social Science Economics and Art, 10(2), 332-334.

[14] Aalto-Setälä, V., \& Raijas, A. (2003). Actual market prices and consumer price knowledge. Journal of Product \& Brand Management, 12(3), 180-192.

[15] Shin, D.-H., Shin, Y.-J., Choo, H., \& Beom, K. (2011). Smartphones as smart pedagogical tools: Implications for smartphones as u-learning devices. Computers in Human Behavior, 27(1), 2207-2214.

[16] Taylor, D. G., \& Levin, M. (2014). Predicting mobile app usage for purchasing and information-sharing. International Journal of Retail \& Distribution Management, 42(8), 759-774.

[17] Venkatesh, V., Morris, M. G., Davis, G. B., \& Davis, F. D. (2003). User acceptance of information technology: Toward a unified view. MIS Quarterly, 27(3), 425-478.

[18] Wu, J. H., \& Wang, S. C. (2005). What drives mobile commerce? An empirical evaluation of the revised technology acceptance model. Information \& Management, 42(5), 719-729.

[19] Lee, H. H., \& Kim, J. (2008). The effects of shopping orientations on consumers' satisfaction with product search and purchases in a multi-channel environment. Journal of Fashion Marketing and Management, 12(2), 193-216.

[20] Chin, W. W., Marcolin, B. L., \& Newsted, P. R. (2003). A partial least squares latent variable modeling approach for measuring interaction effects: Results from a Monte Carlo simulation study and an electronic mail emotion/adoption study. Information Systems Research, 14(2), 189-217.

[21] Tenenhaus, M., Vinzi, V. E., Chatelin, Y.-M., \& Lauro, C. (2005). PLS path modeling. Computational Statistics \& Data Analysis, 48(1), 159-205.

[22] Ringle, C. M., Wende, S., \& Will, S. SmartPLS 2.0 (M3) Beta. Retrieved from the website: http://www.smartpls.de/

[23] Barclay, D., Higgins, C., \& Thompson, R. (1995). The partial least squares (PLS) approach to causal modeling: personal computer adoption and use as an illustration. Technology Studies, 2(2), 285-309.

[24] Fornell, C., \& Larcker, D. F. (1981). Evaluating structural equation models with unobservable variables and measurement error. Journal of Marketing Research, 18(1), 39-50.

[25] Gefen, D., \& Straub, D. (2005). A practical guide to factorial validity using PLS-graph: tutorial and annotated example. Communications of the Association for Information Systems, 16(1), 91-109.

[26] Hsieh, J. J. P.-A., Rai, A., \& Keil, M. (2008). Understanding digital inequality: comparing continued use behavioral models of the socio-economically advantaged and disadvantaged. MIS Quarterly, 32(1), 97-126.

[27] Jang, Y.-T., Chang, S. E., \& Chen, P.-A. (2015). Exploring social networking sites for facilitating 
multi-channel retailing. Multimedia Tools and Applications, 74(1), 159-178.

[28] Cheng, Y.-H., \& Ho, H.-Y. (2015). Social influence's impact on reader perceptions of online reviews. Journal of Business Research, 68(4), 883-887.

[29] Keenan, A., \& Shiri, A. (2011). Sociability and social interaction on social networking websites. Library Review, 58(6), 438-450.

[30] Ojala, A., \& Tyrväinen, P. (2011). Value networks in cloud computing. Journal of Business Strategy, 32(6), 40-49.

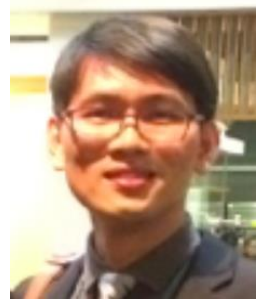

Yu-Teng Jacky Jang is an assistant professor at the Department of Business Administration, Tunghai University in Taiwan. He received his Ph.D. degree in Business Administration from National Chung Hsing University. His research interests include e-commerce, m-commerce, u-commerce, digital marketing, user behavior, information system design, and mobile applications. His publications have appeared in Multimedia Tools and Applications, Security and Communication Networks, International Journal of High Performance Computing and Networking, Journal of Applied Science and Engineering, Journal of e-Business, Asian Journal of Information Technology, INFORMATION: An International Interdisciplinary Journal, and Journal of Organizational Computing and Electronic Commerce. From 2006 to present, totally he has 9 invention patents approved by TIPO (Taiwan Intellectual Property Office).

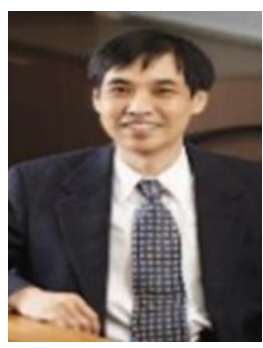

Shuchih Ernest Chang is a distinguished professor at the Institute of Technology Management, National Chung Hsing University (NCHU) in Taiwan. He received his MSCS and Ph.D. from the University of Texas at Austin. Before joining the faculty at NCHU, he worked at UBS Financial Services Inc. in the USA as a Divisional Vice President for five years. He has 15 years of working experience in major computer and financial service firms in the USA, including Unisys, IBM, JP Morgan, Bear Stearns, and UBS. His research interests are in electronic commerce, technology management, financial technology \& applications, enterprise application architecture, information systems, and information security management. His publications have appeared in Journal of Business Research, Computers in Human Behavior, International Journal of Mobile Communications, Multimedia Tools and Applications, Security and Communication Networks, etc. From 2006 to present, totally he has 9 invention patents approved by TIPO (Taiwan Intellectual Property Office).
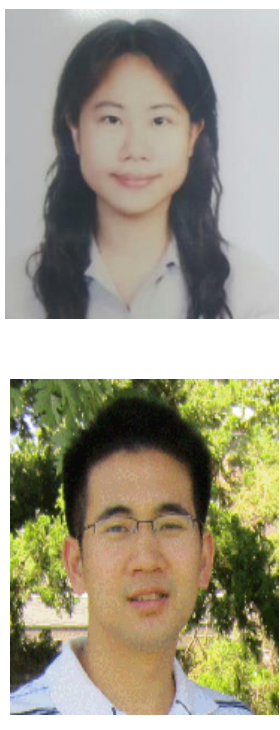

Anne Yenching Liu received her Ph.D. degree in technology management from National Chung Hsing University. She is working currently as an assistant professor in Chihlee Technology University, Taiwan. Her research interests are technology management and electronic commerce. Her publications have appeared in Journal of Business Research, Computers in Human Behavior, Computer Systems Science and Engineering, and Industrial Management \& Data Systems.

Kevin Lai is a research associate in the Mills College Lesson Study Group. He is responsible for performing both qualitative and quantitative data analysis for the group. He received his doctorate in Education with an emphasis in mathematics education from University of California, Davis. His dissertation focused on collaborative learning about geometry for student investigation of quadrilaterals. He also worked as a postdoc in the WISE (Web-based Inquiry Science Environment) group at UC Berkeley. His interests are mathematics education, technology, and student collaboration. 